\title{
Lima y las condiciones cambiantes de la etnicidad
}

\author{
Heraclio Bonilla Mayta \\ Universidad Nacional de Colombia \\ hbonillam@unal.edu.co
}

Para Juan Marchena, por lo que hizo y

seguirá haciendo por nosotros.

A Bernard Lavallé, el amigo de siempre.

\section{RESUMEN}

El presente ensayo da cuenta de los cambios significativos que ha sufrido Lima capital desde su fundación, y con mayor importancia desde la segunda mitad del siglo XX. El impacto que han ocasionado las migraciones del interior del país hacia la capital se refleja no solo demográficamente sino también en el aspecto étnico. El proceso de adaptación de ambas partes, tanto de los residentes limeños como de los migrantes ha devenido en nuevos elementos culturales como los estilos de familia, de vida, de habla, etc.

Palabras clave: Migración, etnicidad, criollo, mestizo, cholo.

\section{Lima and the changing conditions of ethnicity}

\begin{abstract}
This essay gives an account of the significant changes that Lima capital has undergone since its foundation and with greater importance since the second half of the 20th century. The impact caused by migrations from the interior of the country to the capital is reflected not only demographically but also in the ethnic aspect. The process of adaptation of both parties, both residents of Lima and migrants have become new cultural elements such as family styles, life, speech, etc.
\end{abstract}

KeYwords: Migration, ethnicity, creole, mestizo, cholo. 


\section{Preámbulo}

La ciudad de Lima es la capital del Perú, fundada por Francisco Pizarro, cuya estatua se mantuvo hasta hace poco tiempo en uno de los ángulos de la céntrica Plaza de Armas. Hasta los inicios de la segunda mitad del siglo XX mantuvo una vida más o menos apacible, solo interrumpida de tiempo en tiempo por los golpes de estado, convulsiones sociales, temblores y terremotos. Su crecimiento demográfico fue ordenado y su población convenientemente ubicada en espacios y barrios adecuadamente asignados. Hubo una correspondencia entre la situación del poblador y la geografía social y racial de la ciudad. Si la población de barrios populares como el Rímac, La Victoria o los Barrios Altos crecía se ampliaban internamente, los espacios de las viviendas, o estas se añadían a los callejones y "quintas» existentes. Se construyeron urbanizaciones populares para obreros, hubo espacios públicos populares de esparcimiento y los centros de producción fabril estuvieron convenientemente localizadas para no alterar esta armonía. Esa fue la apacible Lima de mi niñez y la de los de mi generación. Era, al menos, la apariencia que seguramente encubría tensiones subyacentes, paliada por una conveniente ideología que daba sustento a ese orden.

Pero desde la década de los 50 del siglo XX esa calma empezó a erosionarse como consecuencia, al igual que en otras ciudades de la América Latina, por los inicios del desplazamiento de la población del interior, tanto de la costa como de la sierra, que en sus inicios fue limitada para convertirse en aluviónica durante las décadas siguientes. Para este análisis importa sobre todo destacar el componente andino de estos migrantes. Fueron varias las razones de este desplazamiento y que han sido analizadas en las numerosas investigaciones realizadas sobre este proceso, entre las cuales deben seńalarse dos: la fractura irreversible en el equilibrio entre tamańo de la familia y las parcelas a disposición de cada familia como consecuencia de la disminución de la tasa de mortalidad por la difusión exitosa de campañas de vacunación, y el «efecto de demostración» de nuevos estilos de vida y de oportunidad en las urbes, a través de mensajes difundidos por radios transistores, particularmente eficaces en el marco de una población todavía analfabeta en su mayor parte. También se sabe los mecanismos utilizados en el desplazamiento: primero los varones en capacidad de producir, solteros o convivientes, que luego atraían a sus familiares, o potenciales migrantes inducidos por compadres o por paisanos.

Los inicios y el proceso de adaptación no fueron fáciles: todo era nuevo, la urbe, la cultura, el ritmo de vida, la adaptación a formas de trabajo distintos a la agricultura. Se sabe, por los trabajos de William Mangin, que en esa adaptación jugaron un papel importante la familia y, más y más, las asociaciones y clubes de paisanos, que fueron gethos de socialización entre conocidos para evocar la nostalgia por el terruño, la música, la comida y, también poco más tarde, como canales de ayuda y de promoción a los pueblos de procedencia. El paisaje social de Lima empezaba a diversificarse con la 
multiplicación de estos «clubes de provincianos» que evocaban la diversidad cultural del país, y cuyas reuniones introdujeron un matiz distinto en la Lima criolla de antaño. Con el tiempo estos mecanismos de amortiguamiento no fueron suficientes y fueron reemplazados por asociaciones de asentamientos humanos, que combinaban paisanaje y residencia, al tiempo que una diferenciación interna dislocaba la solidaridad inicial de los clubes: quienes procedían de familias notables de la provincia se apartaron del resto para formar sus propios clubes, e incluso estos últimos se disgregaban entre los más exitosos en el nuevo entorno, respecto a los de menos fortuna. Pero el marco global era ahora completamente distinto: el entorno de Lima, el desierto y los cerros desnudos vecinos fueron el escenario de vastos conglomerados urbanos, conocidos inicialmente como «barriadas», más tarde y de manera eufemística como «pueblos jóvenes», y cuyo nacimiento fue el resultado de «invasiones» clandestinas o con el respaldo más o menos complaciente de las autoridades locales, cuyas viviendas eran de cartón y de esteras, y carentes al inicio de servicios públicos elementales como agua, desagüe, luz, transporte. No fue un proceso únicamente limeńo, como lo ilustran las "villas miseria» de Buenos Aires o las «callampas» de Santiago de Chile. Como tampoco esa precariedad fue permanente: las esteras fueron reemplazadas por ladrillos, los pisos de tierra fueron cubiertos por cemento o por madera y su interior fue provisto de cocinas a kerosene o de gas, además de refrigeradoras y aparatos de radio y de televisión, para no mencionar los autos estacionados al frente de las viviendas, como tampoco fueron espacios de desposeídos por que extensiones importantes de esas barriadas fueron ocupados por gente de recursos como fuente de alquileres.

\section{El papel de la «arcadia» colonial}

La Lima ordenada antes del gran cambio producido en su paisaje por el desplazamiento de sus migrantes fue posible como resultado de una ideología que encubriera las diferencias entre su población y que los convenciera que hacían parte de un colectivo feliz e inalterable. No existen investigaciones sobre el mecanismo que produjo esa cohesión, más allá de constataciones frívolas que aluden a la "perla del Pacífico», a la "Lima de los Virreyes» al "centro del imperio», para referirse al peso vigente, por lo menos durante la primera mitad del siglo XX, de ese pasado colonial.

La ausencia de investigaciones ha sido sustituida por ensayos, en los que la evidencia se reemplaza por observaciones, por intuiciones a veces razonadas, de las que los 7 ensayos de interpretación de la realidad peruana de José Carlos Mariátegui constituyen un ejemplo pertinente. Para el caso de la Lima de los cincuenta su mejor y más radical lo constituye el pequeño libro de Sebastián Salazar Bondy, un escritor limeño quien publicó en 1964, un año antes de su temprana muerte, un pequeño libro que tituló 
Lima la horrible. Epíteto para designar a la «arcadia» colonial que pensaba era la ciudad en su papel de impostura, de ocultamiento de la realidad, de añoranza del pasado como escape al presente y de rechazo al futuro. Esa ideología y esa imagen fueron construidas por las grandes familias no solo para sí misma, sino para todo el resto.

Una expresión de esa asimilación por la arcadia es el "criollismo», afirma Salazar Bondy (1974): «El criollismo limeño vendría a ser, pues, el nacionalismo limeño, o sea, un sucedáneo del verdadero nacionalismo» (p. 28), donde «...muchas son las contrapuestas realidades históricas y actuales que están consideradas como formas supinas del criollismo...La contradicción es, a fin de cuentas, la prueba de que este costumbrismo tiene un doble fondo: al exaltar el régimen virreinal, exalta la opresión de que se nutría la opulencia dorada del antiguo señorío» (p. 29). Continúa: «Es también viveza criolla... ¿qué es esa viveza? Una mixión, en principio, de inescrupulosidad y de cinismo. Por eso es en la política donde se aprecia mejor el atributo. En síntesis, consiste en la flexibilidad amoral con que un hombre deja su bandería y se alinea en la contraria, y en el provecho material que saca, aunque defraude a los suyos, con el cambio» (p. 31). Pero advierte «el vivo de esta laya se da, no obstante, en todas las esferas de la actividad...Los otros, los que proceden de acuerdo a su conciencia o a la ley, son tontos. En vivos y tontos, dentro de la maniquea psicología criollista, se divide la humanidad» (pp. 32-33). Para el hombre común es la escalera del ascenso, gracias al ejercicio del criollismo se obnubila, se embriaga de mentiras, sueña con el señorío (p. 35)... La arcadia colonial es la envoltura patriotera y folklórica de un contrabando (p. 37).

Pero estas grandes familias no son un universo cerrado, cambian cuando es preciso, salvo en un punto "que constituye su más preciado blasón: la segregación de la mayoría india y mestiza y, lo que es peor, pobre inevitablemente pobre, dentro del sistema cerrado de las castas» (p. 47). No obstante, este hermetismo, anota el autor, «recientemente y como recurso de emergencia, del criollismo colonialista ha sido algo más que una fábula en boca de los voceros de la nobleza, de las grandes familias. Ha tenido que convertirse en práctica, y las danzas populares, los capitosos manjares de la mesa humilde, la jerigonza coloquial —incluso en su modalidad de bajo fondo, la replana... toda la múltiple variedad de lo criollo antes más mentado que practicado, han sido incorporados a los salones dela vieja prosapia... A esto le llaman nuestros burgueses aristócratas democratización» (pp. 47-48).

Y en ese contexto Salazar Bondy se pregunta: «¿Cómo se conduce la masa popular?» Responde: ... el pueblo es igual a la noche de Lima: suave no se violenta. Y la masa popular transcurre, debido a ello, sin grandes pasiones (o en todo caso, ocultándolas o sublimándolas (pp. 56-57). Buscan el ascenso social y en esa lucha prepondera el individualismo. $\mathrm{Al}$ pueblo... «se les martilla, una y otra vez en toda ocasión, que el 'triunfo' depende únicamente del sumiso trabajo y del acatamiento de la organización de la sociedad tal cual es» (p. 60). Abrigan, por cierto, el deseo de cambio, pero «las puertas de la riqueza 
se abren en la lotería, en el juego hípico, en el golpe de suerte.» (p. 62). Concluye: «una vital desgana, que médanos y nieblas enmarcan, priva en los actos de la humilde gente que acepta la fatalidad de su existencia» (p. 64).

Esta armazón se traduce en el habla cotidiano, de la cual la lisura es su mejor expresión. Afirma el autor «cura en salud y se contradice, pues golpea y acaricia, agravia y se excusa, afrenta y se rectifica... el inventario de la lisura nos revela un contenido que conlleva una secreta atadura: impedir la protesta, segar la rebeldía y la violencia creadora de las mayorías en su nacimiento» (pp. 113-114). Eso explica que la disidencia de González Prada se expresara, como recuerda Salazar Bondy, conminando a romper el pacto infame de hablar a media voz. Pero fracasó. Afirma Salazar Bondy: «El fracaso de sus proyectos revolucionarios — que acogieron dos generaciones faltas de su integridad, la de sus discípulos inmediatos y la de Haya de la Torre- debe cargarse a la cuenta de la vasta capacidad corruptora del colonialismo, experto más en anemizar que en aplastar sus anticuerpos» (p. 152). La valla de la lisura en el habla, en el comportamiento público que condena el actuar por fuera de las fronteras de su grupo irroga la terrible condena que condensa la palabra huachafo. Huachafo, huachafoso, huachafiento, y su equivalente femenino, son connotaciones de la huachafería, utilizada para denostar el comportamiento de los pobres que aparentan ser lo que naturalmente no debieran. «He aquí el sentido del huachafismo: lo califican despectivamente quienes desde la cima que detentan arbitran el favor del escalafón y, avisándolo, se defienden, más también encarna la aspiración, de contenida agresividad, de quienes intentan escalar dicha cumbre social» (p. 118).

Impacta y subyuga la caracterización política y cultural que hace Salazar Bondy de las grandes familias, de la misma manera cómo y por qué interiorizan sus valores los grupos populares y los mecanismos de descalificación que utilizan las primeras para juzgar a quienes no se atreven a jugar las «reglas del juego». Pero ¿fue así realmente? Se trata de un ensayo, como se dijo, que combina el insight y la experiencia de un limeño sensible como él, y por lo tanto no es posible aplicar a su trabajo los protocolos académicos más estrictos, sobre todo cuando Lima la horrible fue unánimemente celebrada desde su aparición como un diagnóstico preciso y una condena moral justificada del comportamiento de la clase propietaria. No obstante, ese relato requiere algunas precisiones. Es correcto, para empezar, reconocer la perdurable impronta de los valores coloniales en la oligarquía limeña, blanca y cerrada y hasta hace poco, así como el referente fundamental de España en su conducta y en su identidad. Es suficiente, para probarlo, el angustioso seguimiento de su prensa a los acontecimientos cotidianos de la Guerra Civil Española entre 1936 y 1939. No es menos cierto su señalamiento de las maneras sutiles y otras obvias de como la identidad y las aspiraciones de las clases populares fueron modeladas e impuestas por los dominantes, y eso se hizo desde el alba del sistema colonial y por eso la metrópoli nunca requirió para guardar a sus rebaños ni policías 
ni ejército. Además en realidades que no experimentaron una transformación violenta como México en 1910, en Bolivia en 1952, o en la Cuba de 1959, esa impronta colonial fue irrecusable e inconmovible, sobre todo en los estereotipos de conducta y en los mecanismos de control y de reproducción de esos valores coloniales.

No obstante, para utilizar una frase coloquial que a Salazar Bondy le hubiese encantado, fue la sociedad peruana en el contexto en que escribe su libro, ¿̨la "calma chicha» que emerge como imagen de su lectura? Probablemente la representación de esa realidad sea la que ofrece el autor y que comparten mucho de sus lectores, pero la realidad subyacente fue mucho menos «arcádica». La ausencia de investigaciones sobre la composición de la clase dominante permite tal vez subrayar su homogeneidad como grupo y no tomar en cuenta sus fracciones y fricciones internas, pero no se puede desconocer que los sectores populares tuvieron una presencia violenta y Salazar Bondy recuerda con razón el levantamiento de Túpac Amaru, el cacique de Tungasuca, en el lejano ocaso del régimen colonial. Pero no fue el único. Campesinos indios de la sierra central aprovecharon el grotesco colapso del civilismo, el partido de los criollos limeños durante la guerra contra Chile entre 1879 y 1884 para plantear con las armas en la mano sus reivindicaciones, y lo mismo ocurrió un ańo después en la sierra norte con Atusparia, y antes de la guerra lo hicieron con el levantamiento de los hermanos Gutiérrez en su protesta contra Balta y contra Manuel Pardo, el más connotado oligarca del siglo XIX.

Pero fue en la primera mitad del siglo XX que esas movilizaciones se expresan con una mayor contundencia. Empezaron entre 1912 y 1914, en el breve gobierno de Guillermo Billinghurst, que al decir de algunos quiso practicar un "populismo» prematuro, reconociendo el derecho de los obreros a la protesta, a la organización, y a no trabajar más de ocho horas diarias. Frente a la oposición cerrada de la clase propietaria, que decidió derrocarlo con Oscar R. Benavides al frente, los trabajadores de Lima protestaron. Pero esto fue el preludio de acontecimientos mucho más dramáticos que están aún presentes en la memoria colectiva del país. Por ejemplo, la caída de quien quería forjar una "patria nueva», don Augusto B. Leguía, no fue un lecho de rosas ni un arreglo de salón. Murió en la prisión y fue el inicio de una guerra abierta entre las fuerzas del oficial que lo derrocó, Luis M. Sánchez Cerro y sus seguidores organizados en la Unión Patriótica, las huestes de la derecha en las que ya descollaba José de la Riva Agüero, y el naciente Partido Aprista de Víctor Raúl Haya de la Torre. Luego, julio de 1932, en que centenares de militantes apristas y varios oficiales fueron masacrados en el complejo arqueológico de Chan Chan en el norte, seguido por el asesinato de Sánchez Cerro en abril de 1933 y del propietario del diario El Comercio, poco después. Fue el inicio de las catacumbas para los apristas, la larga y agónica "travesía del desierto", con asonadas y protestas múltiples que hacen parte de la leyendaria tradición política de ese Partido. Eso forjó la identidad de los apristas durante mucho tiempo, a la vez que los distanció del Ejército. Epopeya que fue recordada una y otra vez por sus dirigentes 
y militantes, incluso si su Jefe Máximo estuvo en las catacumbas, preso, o desterrado fuera del país o en la Embajada de Colombia. No, todo eso no configura un cuadro armonioso, en virtud de la cual los humildes esperaron que el maná les cayera del cielo, ni que la Arcadia colonial los adormeciera. El juicio de Bourricaud en su libro clásico Poder y sociedad en el Perú me parece en este contexto un balance apropiado, cuando escribe: «Los valores del criollismo están lejos de ser reconocidos y tenidos por legítimos por toda la clase media». Sebastián Salazar Bondy solo habla de la arcadia colonial para denunciar esta demasía. Con su libro Lima la horrible se alinea junto a las voces de protesta y de disidencia. Pero entre la adhesión y el rechazo me sentiría inclinado a discernir una operación de compromiso en cuya virtud quienes a ella se entregan se aplican a sí mismos los rasgos negativos de la cultura criolla, para rendir homenaje a la oligarquía, a todos sus rasgos favorables. Una "criollada» califica la indelicadeza del ambicioso de baja extracción; en la expresión "criollazo» se encuentra también la idea de astucia vulgar y basta. Ni una ni otra de estas expresiones son aplicables a la "gente», a «nuestra sociedad»; van de suyo cuando se trata de un político, de un periodista deshonesto, de un abogado inescrupuloso, todas ellas gentes de clase media» (p. 98).

Tampoco los exponentes de la aristocracia intelectual de ese momento avalaron y sacralizaron unánimemente y sin cortapisas el papel positivo de ese legado colonial. El caso más paradójico es el de José de la Riva Agüero, aristócrata de cuna, quien por lo menos antes de su conversión al fascismo, a su regreso de Europa, escribió a raíz de su viaje a la sierra sur en 1912 sus reflexiones al borde la Pampa de la Quinua, escenario de la batalla final de Ayacucho en 1824: «El relato de mi peregrinación sería ineficaz e inútil sino fuera sincero; y debo a mis lectores y a mí mismo la confesión de mis impresiones exactas. Mi sentimiento patrio que se exaltó con las visiones del Cuzco y las orillas del Apurímac, no sacó del campo de Ayacucho, tan celebrado en la literatura americana, sino una perplejidad inquieta y triste. En este rincón famoso, un ejército realista compuesto en su totalidad de soldados naturales del Bajo y del Alto Perú, indios, mestizos y criollos blancos, y cuyos jefes y oficiales peninsulares no llegan a la décima octava parte del efectivo, luchó con un ejército independiente, del que los colombianos constituían las tres cuartas partes, los peruanos menos de una cuarta, y los chilenos y porteños una escasa fracción. De ambos lados corrió sangre peruana. No hay por qué desfigurar la historia: Ayacucho en nuestra conciencia nacional, es un combate civil entre dos bandos, asistido cada uno por auxiliares extranjeros. Entre los aliados sudamericanos reunidos aquí, bullían ya, aún antes de obtenida la emancipación, los odios capitales, como niñeros los gemelos bíblicos desde el seno materno» (Riva Agüero, 1969).

En 1967, tres años después de publicado el libro de Salazar Bondy, François Bourricaud, el sociólogo francés, publicó la versión original del libro mencionado antes. Fue uno de esos distinguidos peruanistas, que fascinado por la experiencia que tuvo 
años antes realizando estudios sobre la sociedad rural de Puno, en el sur del país, ofreció una visión de conjunto sobre la sociedad política peruana, incluyendo en su análisis la naturaleza de su oligarquía. No fue un estudio sistemático, sino una visión ofrecida con sensibilidad e inteligencia, y a partir del estudio de periódicos, revistas y novelas sobre el Perú de mediados del siglo XX. Fue importante, entre otras razones, porque dio origen a una extensa discusión sobre el poder oligárquico y las formas de movilización de los sectores medios encuadrados dentro de las principales fuerzas políticas, es decir el Apra, Acción Popular y los diversos grupos de la izquierda. Es un análisis que propone una visión de una sociedad en movimiento, válida hasta ese momento, pero que no pudo dar cuenta de los dramáticos cambios que se dieron en el Perú después de 1967.

\section{El desborde}

El término fue acuñado por el antropólogo peruano José Matos Mar como título de su libro Desborde popular y crisis del Estado. El nuevo rostro del Perú en la década de 1980 y cuyo contenido enfatizaba un fenómeno nuevo como era la migración aluviónica hacia Lima desde la década de los 50 del siglo pasado. El libro y el calificativo se hicieron populares como lo evidencian las sucesivas ediciones del texto. El autor estuvo particularmente calificado para esa tarea porque gran parte de su trabajo profesional lo dedicó al estudio de la migración y de la formación de las «barriadas», volcados en libros como Las barriadas de Lima, 1957. El conjunto de sus investigaciones, finalmente, fue difundido en el importante libro Perú. Estado desbordado y sociedad nacional emergente publicado por la Universidad Ricardo Palma de Lima en el año 2016. El contenido de ese libro, que no ha merecido a mi conocimiento una evaluación profunda, constituye la base para tres órdenes de reflexiones: a) la transformación del paisaje urbano de Lima, b) su significado en la nueva configuración de las relaciones étnicas y de clase; c) las implicancias económicas y políticas de ese desborde.

En relación a lo primero, algunos guarismos permiten configurar el contexto. Según los Censos la población peruana alcanzó en 1961 los 9'909,746 millones; en 1972 13'538, 208; en 1981 17'005,210; en 1993 22'048,356 y en 2007 27'412,157. De ese total, la población urbana para esos años fue, respectivamente, 4'698,178; 8’058,495; $11^{\prime} 091,923 ; 15^{\prime} 458,599 ; 20^{\prime} 810,288$, es decir que representó frente a la población total un $47.4 \%$ en 1961; un 59.5\% en 1972 un $65 \%$ en 1981 ; un $70.1 \%$ en 1983 ; y un $75.9 \%$ en el 2007. A diferencia de la primera mitad del siglo XX, se produjo entonces un volcamiento de las áreas rurales a ciudades importantes como Lima. Pero, ¿̧se trata de una «urbanización» o de una «ruralización» de la ciudad?

Dentro de este proceso de migración se inscribe el fenómeno de las barriadas. Informa José Matos que entre 1950 y 1990 hubo diez grandes barriadas, contando 
cada una de ellas entre 200 y 500 mil habitantes, es decir más de 4 y medio millones de habitantes (p. 76). La primera fue San Cosme que se formó en 1946, seguida por El Agustino en 1947 y San Martín de Porras en 1949 (p. 79). En las décadas siguientes no solamente su número creció sino que experimentaron cambios tanto internos como externos, figurando entre los últimos el convertirse en la sede de organizaciones políticas locales como los distritos y, más tarde, en parte de inmensos conglomerados conocidos como Lima Norte (San Martín de Porras, Comas, Independencia, Los Olivos y Ventanilla; Lima Este (El Agustino y San Juan de Lurigancho); y Lima Sur (San Juan de Miraflores, Villa María del Triunfo y El Salvador). Estos «conos», como son conocidos por el habla popular, concentran las dos terceras partes de la población total de Lima y son centros importantes de producción y de comercio, movilizando considerables sumas de capital dinero.

Nacieron de ocupaciones clandestinas, en el marco de un ritual (banderas, invocación de santos, nombres de políticos prominentes) para no ser tempranamente desalojados, y su ocupación empezó con los cerros aledaños (San Cosme), continuó luego con los terrenos planos (27 de Octubre) para llegar después a los desiertos del sur (p. 108). Pero no fue un proceso uniforme porque hubo momentos en los cuales la ocupación fue más intensa, como ocurrió durante el segundo gobierno de Manuel Prado, entre 1956 y 1961, con un total de 104 invasiones. Estos gobiernos interpretaron este desborde, dice Matos, como un problema de vivienda (p. 109), siendo la sierra peruana la principal fuente del desplazamiento hasta 1960 (p. 112).

En el proceso de asentamiento al inicio contaron con el respaldo de la familia nuclear, luego los compadres, finalmente los paisanos, pero la cohesión fue igualmente asegurada mediante la implementación de ritos como los bautizos de personas y de viviendas. Un nivel adicional de organización fue el nacimiento de la asociación de pobladores, cuya dirigencia asumiría la responsabilidad de gestionar ante las autoridades locales desde el reconocimiento como centro poblado hasta la dotación de servicios como agua, luz y baja policía. En el censo organizado por José Matos y sus alumnos de la Universidad Nacional Mayor de San Marcos en 1955 encontraron que el 52.4\% de la población de las barriadas nacieron en Lima y Callao, que el 30\% eran económicamente activos, con el predominio de obreros, empleados y obreros independientes y que sus rangos de ingresos era muy variado; no eran precisamente miserables, además que algunos ocuparon las barriadas para tener una vivienda propia aun teniendo la capacidad de pagar un alquiler (p. 129). En 1956 la población de las barriadas era de 108,988 habitantes y la de Lima, según el censo de 1940, 1’260,829, de modo que la primera era $9.5 \%$ del total de la población limeña. Al mismo tiempo semejantes centros poblados surgían en Arequipa y en Chimbote, la primera agrupando un 13.4\% del total y la segunda con un $21.4 \%$. En el caso de Chimbote esa aglomeración se explica por 
el surgimiento de la siderurgia y las primeras plantas de procesamiento de la harina de anchoveta.

La conversión de algunas barriadas como sedes de distrito a lo largo de la década de los 50 y 60 del siglo pasado, como 27 de Octubre, San Martín de Porras, Comas y Villa María del Triunfo, fue parte de una estrategia de convertirlos en propietarios, y de parte de los pobladores de poder acceder a recursos complementarios, proceso que convirtió a las barriadas en siete distritos nuevos (p. 155). Este proceso alarmó primero a los propietarios de los fundos aledańos, pero luego sacaron provecho al urbanizar estos terrenos, constituyendo empresas que aprovechaban del plus valor urbano. Al mismo tiempo, la heterogénea composición de los pobladores de las barriadas se expresó en diferencias en la ocupación de los espacios: en Comas, en 1985, el 6.3\% de la población vivía en las barriadas y el $38.3 \%$ en urbanizaciones, y eso fue apenas una de las manifestaciones de las profundas diferencias al interior de estos centros poblados. Cinco décadas más tarde, las barriadas condensan una población mucho más significativa: en el 2010 existen en el Perú 7,419 barriadas, tres mil de las cuales están ubicadas en Lima, con una población que sobrepasa diez millones (p. 348).

Con la explosión de la población barrial y el deterioro de la situación económica de la población popular los mecanismos iniciales de solidaridad basados en el parentesco, el compadrazgo y el paisanaje no fueron ya suficientes y dieron paso a nuevas e ingeniosas formas de ayuda mutua y de apoyo. Fue el caso de los "comedores populares", convertidas después en Clubes de Madres, y de los «vasos de leche». En 1989 hubo 1500 comedores y 7500 comités de vasos de leche con más de 100 mil participantes (p. 240). Pero hicieron parte también de la movilización popular a través de paros, y estuvieron en el centro del fuego cruzado entre Sendero Luminoso y las fuerzas de represión, además que experimentaron la acción de pandillas juveniles de delincuentes que en 1980 llegaban a 700. (p. 243).

¿Qué significa este aluvión de gente en la Lima de antaño y cuya imagen fue evocada con fuerza en la Lima la horrible de Sebastián Salazar Bondy? Es esta la segunda coordenada de análisis en este apartado. Es evidente el incremento de los sectores populares, integrados por costeños y por serranos. Pero estos últimos no son más indios y andinos, porque igualmente experimentaron un proceso interno de cambio que no los convirtió en mestizos como argumentaba antes la Antropología Cultural, eran y son cholos, grupo cuyas características y estilo de vida fue oportunamente analizado por François Bourricaud y por Aníbal Quijano. No tienen la ambivalencia de los primeros sino que expresan el orgullo de su identidad, y luchan por su reconocimiento. Pero, con todo, no son un grupo homogéneo porque se diferencian por ingresos, por el trabajo, por el lugar de la residencia, oposiciones que la cultura no termina por ocultar. Tienen música propia, un habla peculiar, e idolatran a santos que las autoridades religiosas no reconocen como la famosa «Sarita Colonia». Es una suerte de "cultura híbrida», de la que hablaba 
Néstor García Canclini y cuyas manifestaciones más evidentes se encuentran en estas poblaciones marginales. En este contexto la etnicidad, sí existe, está cruzada por otras señales identitarias que remiten a la economía, al lugar de procedencia e incluso a los barrios de residencia. La profunda inestabilidad de esta situación, la ausencia de un universo coherente en esta identidad, la salida profundamente individual que caracteriza su búsqueda de mejores oportunidades, la transgresión a las reglas de su propio grupo, calificado por Luis Pásara como el "achoramiento», están muy lejos de las viejas solidaridades étnicas y de clase. Más bien, los convierte en profundamente proclives al llamado plebiscitario de cualquier aventurero de la política, por encima incluso de formas convencionales de organización como los partidos políticos. Los nuevos movimientos sociales expresan esta situación: son importantes cuando reclaman los derechos de una población, de una región, pero son efímeros por la naturaleza misma de sus demandas, desaparecen cuando ellas son satisfechas incluso cuando no lo son. Pensar esta realidad implica ir más allá de la descripción de las barriadas para conocer la composición de las mismas y toda la heterogeneidad que cobijan y que puede terminan disgregándolas.

La tercera coordenada tiene que ver con las implicancias políticas y económicas de este desborde. Comenzaré comentando lo primero a partir de las conclusiones que establece José Matos Mar en su importante libro. Él escribe: «En la última década del siglo XX los migrantes se habían modernizado, eran ciudadanos peruanos. Para lograrlo trazaron una relación distinta con el estado, a la que hemos denominado desborde. En la mayoría de los casos sus organizaciones no se enfrentaban al estado, sino que requerían su arbitraje, no se oponían a la Ley sino que reclamaban su cumplimiento, no desconocían a la institucionalidad del Perú oficial sino que la utilizaban para el logro de sus propósitos. Ejemplo de lo cual al culminar la década de 1980 se logró la distritalización de la mayoría de los conos de Lima. Abre a los pobladores el universo de la municipalidad y de la participación local y los educa en el ejercicio aunque sea limitado del poder político. Ello porque el sistema político requería de sus votos. Ciudadanos incompletos colectivos y no individuales, ciudadanos sólo políticos y no económicos pero ciudadanos al fin» (p. 250). Bien, a condición que se recuerde que las comunidades de indígenas, universo que conoce igualmente muy bien José Matos, hicieron lo mismo al exigir del estado su reconocimiento como tales para lograr el amparo y los beneficios del Estado y de la Constitución. Exigen unos y otros sus derechos como ciudadanos y no la gracia a la que aspiraba el vasallo, con la condición de no cuestionar el orden imperante y de ingeniarse múltiples mecanismos de sobrevivencia ante el desdén de los de arriba.

En lo que concierne a las implicancias económicas de este desborde, el autor afirma que en la Lima metropolitana la pobreza extrema ha desaparecido aunque en los confines de la provincia siga involucrando a las 3/5 partes de la población (p. 416), afirmación que las estadísticas oficiales reiteran con satisfacción al afirmar el descenso, paulatino y mínimo de la pobreza, medidos además en deciles. Incluso fue ensalzado que 
en años recientes el crecimiento del PIB global fue el mayor de la región, pero se oculta convenientemente que este crecimiento, al igual que antes, se deben a factores que escapan al control completo del Estado y que son más bien el resultado del incremento del precio de las materias primas demandadas por potencias como la India, China, o el Brasil de algunos años. Aún más, se prescinde en señalar que la exitosa exportación de esas rentas naturales tiene una débil incidencia en la ampliación del mercado laboral, y sólo favorece a los propietarios o a la pequeña fuerza laboral ya establecida. En este contexto, tanto observadores externos como internos quedan extasiados al constatar la presencia de núcleos económicamente dinámicos en esos barrios populares, la conversión en emporios mercantiles prósperos como en Gamarra (La Victoria), y la existencia de centros comerciales, financieros y de entretenimiento como los existentes en los conos Norte y Sur. Para que esto ocurra, como lo señala Jaime de Althaus (2007)en su meditado libro La revolución capitalista en el Perú, la brutal política de estabilización introducida por Alberto Fujimori y la cancelación de los privilegios rentistas asignados por los gobiernos previos a la clase propietaria fueron necesarios. Pero esa bonanza fue segmentada, profundamente desigual, favoreció a pocos en detrimento de las mayorías, además que la carencia de investigaciones sobre los eslabonamientos internos de esas empresas exitosas, para no mencionar las severas restricciones que impone el entorno internacional, impiden una conclusión más convincente.

Lima cambió, en resumen, pasó de la Arcadia y del ensueño a ser un inmenso conglomerado con más de veinte millones de habitantes, y cuyo incremento se debe sobre todo a la migración interna, cuyo dinamismo inspira a la vez esperanza e inquietud. Esas mayorías no tienen el control de su destino, ni siquiera cuentan con la garantía mínima de un trabajo estable y decoroso, para no mencionar de servicios de salud y educación, sino que están a la merced no de las oligarquías del pasado, pero sí de formas oligárquicas de control y de exclusión.

\section{Referencias bibliográficas}

De Althaus, J. (2007). La revolución capitalista en el Perú. Lima: Fondo de Cultura Económica. Matos Mar, J. (1956). Las barriadas de Lima, 1957. Lima: Instituto de Estudios Peruanos.

Matos Mar, J. (1984). Desborde popular y crisis del Estado. El nuevo rostro del Perú en la década de 1980. Lima: Instituto de Estudios Peruanos.

Matos Mar, J. (2016). Perú. Estado desbordado y sociedad nacional emergente. Lima: Universidad Ricardo Palma.

Riva Agüero, J. (1969). Paisajes peruanos. Lima: Universidad Católica, pp. 152-153. 